\title{
Successive Potentiometric Titration of Iron(II) and Iron(III) with Cobalt(II) in the Presence of 1,10-Phenanthroline
}

\author{
Mariko Kuwabara, Hideyuki Katsumata, Norio Teshima, Makoto Kurihara \\ and Takuji KAWASHIMA ${ }^{\dagger}$
}

Laboratory of Analytical Chemistry, Department of Chemistry, University of Tsukuba, Tsukuba 305-8571, Japan

\begin{abstract}
A novel potentiometric titration of iron(II) and iron(III) is proposed. The method is based on the effect of 1,10-phenanthroline (phen) on the redox reactions of chromium(VI) and iron(III) with cobalt(II). In the presence of phen the conditional redox potential of the $\mathrm{Co}(\mathrm{III}) / \mathrm{Co}$ (II) system falls below those of the $\mathrm{Cr}(\mathrm{VI}) / \mathrm{Cr}$ (III) and $\mathrm{Fe}(\mathrm{III}) / \mathrm{Fe}$ (II) systems at $\mathrm{pH}$ around 1. Therefore, chromium(VI) and iron(III) can be titrated with cobalt(II) in the presence of phen, alternatively. Firstly, to a sample solution containing iron(II) and iron(III), a known amount of chromium(VI) is added in excess at $\mathrm{pH}$ around 1, so that iron(II) can be oxidized to iron(III) in the absence of phen. After the pretreatment, the sample solution containing the excess of chromium(VI) and iron(III) (total iron) is titrated with a standard cobalt(II) solution in the presence of phen. The concentrations of iron(II) and iron(III) can be calculated from the first and second potential breaks at the equivalence points for the titration. The relative standard deviations of this method were 0.66 and $0.81 \%$ for four determinations of $5 \times 10^{-4} \mathrm{~mol} \mathrm{dm}^{-3}$ iron(II) and $1 \times 10^{-3} \mathrm{~mol} \mathrm{dm}^{-3}$ iron(III), respectively. The proposed method was successfully applied to the determination of total iron in standard iron-ore samples (JSS No. 801-4, 814-1 and 850-4) and to the successive determination of iron(II) and iron(III) in a Mosan iron-ore sample (JSS No. 812-3).
\end{abstract}

Keywords Effect of ligand, potentiometric titration, iron(II), iron(III), chromium(VI), cobalt(II), 1,10-phenanthroline

The chemical speciation ${ }^{1,2}$ and simultaneous determination $^{3}$ of metal ions have been increasingly needed in areas such as clinical chemistry, environmental pollution and industrial control. Iron is present as bivalent and trivalent states in the natural environment. The changes between these two forms of iron are important in various biological ${ }^{4}$ and geochemical ${ }^{5}$ processes. Thus, the development of a simultaneous method for iron(II), iron(III) and thus the total iron is still desired. The redox potential of a system involving metal ions is modified by complexation of metal ions with a suitable ligand. ${ }^{6}$ Vydra and Pribil ${ }^{7,8}$ reported on the effect of 1,10-phenanthroline (phen) on the redox reaction of cobalt(II) with iron(III) and developed a method for the potentiometric titration of cobalt(II) with iron(III) in the presence of this ligand. By using this phenomenon, we have recently proposed novel redox systems, which are applicable to potentiometric titrimetry for the determination of metal ions. ${ }^{9-13}$ In the presence of phen or $2,2^{\prime}$-bipyridine (bpy), a remarkable potential break is observed in the titration of vanadium(IV) with iron(III), cobalt(II) with vanadium(V) and cobalt(II) with chromium(VI). ${ }^{11}$ Furthermore, we have reported on the successive potentiometric titration of chromium(VI) and iron(III) with cobalt(II) in the presence of phen. ${ }^{12}$ We also developed a new flow-injection spectrophto-

To whom correspondence should be addressed.

N. T. present address: Department of Applied Chemistry, Aichi Institute of Technology, Toyota 470-0392, Japan. metric method for the simultaneous determination of vanadium(IV) and vanadium(V), based on the effect of phen and diphosphate on the redox potential of the $\mathrm{Fe}(\mathrm{III}) / \mathrm{Fe}(\mathrm{II})$ system. $^{14}$ In this paper, the successive potentiometric titration of chromium(VI) and iron(III) ${ }^{12}$ is further developed, that is, successive potentiometric titration of iron(II) and iron(III) with cobalt(II) is presented. The redox potential of the $\mathrm{Cr}(\mathrm{VI}) / \mathrm{Cr}(\mathrm{III})$ system is higher than that of the $\mathrm{Fe}(\mathrm{III}) / \mathrm{Fe}$ (II) system at low $\mathrm{pH}$. Thus, iron(II) was oxidized to iron(III) by adding excess chromium(VI) as an oxidizing agent before the titration. Then, non-reacted chromium(VI) and total iron were titrated with cobalt(II) in the presence of phen. The present method can determine iron(II) and iron(III) in the range $3 \times 10^{-4}-1 \times 10^{-3} \mathrm{~mol}$ $\mathrm{dm}^{-3}$; the relative standard deviations of this method were 0.66 and $0.81 \%$ for four determinations of $5 \times 10^{-4}$ mol dm ${ }^{-3}$ iron(II) and $1 \times 10^{-3} \mathrm{~mol} \mathrm{dm}^{-3}$ iron(III), respectively. The method was successfully applied to the determination of total iron in standard iron-ore samples and to the successive determination of iron(II) and iron(III) in a Mosan iron-ore sample issued by The Japan Iron and Steel Federation.

\section{Experimental}

\section{Reagents}

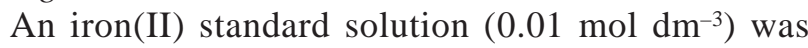
prepared daily by dissolving $0.098 \mathrm{~g}$ of iron(II) ammonium sulfate hexahydrate (Mohr's salt) in $50 \mathrm{~cm}^{3}$ of 0.01 
mol $\mathrm{dm}^{-3}$ sulfuric acid and stored in a nitrogen atmosphere; it was then standardized with standard potassium permanganate. A stock solution of iron(III) (0.01 mol $\mathrm{dm}^{-3}$ ) was prepared by dissolving $0.48 \mathrm{~g}$ of iron(III) ammonium sulfate dodecahydrate in $100 \mathrm{~cm}^{3}$ of 0.01 mol dm $\mathrm{dm}^{-3}$ sulfuric acid and standardized with EDTA. A solution of chromium(VI) $\left(0.01 \mathrm{~mol} \mathrm{dm}^{-3}\right)$ was prepared by dissolving $0.15 \mathrm{~g}$ of potassium dichromate (primary standard) in $100 \mathrm{~cm}^{3}$ of $0.5 \mathrm{~mol} \mathrm{dm} \mathrm{dm}^{-3}$ sulfuric acid. A cobalt(II) solution $\left(0.04 \mathrm{~mol} \mathrm{dm}^{-3}\right)$ was prepared by dissolving $4.75 \mathrm{~g}$ of cobalt(II) chloride hexahydrate in 500 $\mathrm{cm}^{3}$ of $0.05 \mathrm{~mol} \mathrm{dm} \mathrm{dm}^{-3}$ sulfuric acid and standardized with EDTA. Working solutions of metal ions were prepared by suitable dilution with $0.01 \mathrm{~mol} \mathrm{dm}^{-3}$ sulfuric acid. A phen solution $\left(0.2 \mathrm{~mol} \mathrm{dm}^{-3}\right)$ was prepared by dissolving an appropriate amount of the reagent in 0.5 mol $\mathrm{dm}^{-3}$ sulfuric acid. All reagents used were of analytical-reagent grade, and were used without further purification. All solutions were prepared with deionized water purified with a Milli-Q PLUS system.

\section{Apparatus}

All potentiometric titrations were performed using a Mitsubishi Chemical Model GT-07 automatic titrator equipped with a Mitsubishi Chemical Model GTPR10 combination platinum electrode (reference electrode is a silver-silver chloride) and a Model GT5TSN thermometer. A Horiba Model F-8 AT pH/mV meter was used for the $\mathrm{pH}$ measurements with a Horiba combination electrode (\# 6028-10T). A Sibata control unit CU85 thermostat was used to maintain a constant temperature. The titration vessel was a specially ordered fivenecked flask (for micro-burette, electrode, thermometer and inlet and outlet of nitrogen gas) with a water jacket.

\section{Procedure}

To a $50-\mathrm{cm}^{3}$ volumetric flask, $2.5 \mathrm{~cm}^{3}$ iron(II) $(0.01$

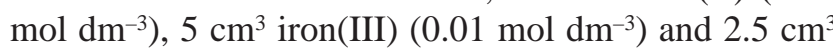
chromium(VI) $\left(0.01 \mathrm{~mol} \mathrm{dm}^{-3}\right)$ solutions were taken. The $\mathrm{pH}$ of the solution was adjusted to about 1 with 1 mol $\mathrm{dm}^{-3}$ sulfuric acid by checking the $\mathrm{pH}$ with a $\mathrm{pH}$ meter. Under this condition, the chromium(VI) added to the sample solution completely oxidized iron(II) to iron(III). Then, $10 \mathrm{~cm}^{3}$ of phen $\left(0.2 \mathrm{~mol} \mathrm{dm} \mathrm{dm}^{-3}\right)$ was added and the $\mathrm{pH}$ of the solution was readjusted to around 1. The solution was then diluted to the mark with water. A $20 \mathrm{~cm}^{3}$ aliquot of the solution was transferred to the titration vessel and nitrogen gas was bubbled through the solution for 30 min before titration. The solution was then titrated with a standard cobalt(II) solution $\left(0.01 \mathrm{~mol} \mathrm{dm}^{-3}\right)$. Similarly, the potential values were recorded automatically when the potential change was within $\pm 2 \mathrm{mV} \mathrm{m^{-1 }}$ for each addition. All titrations were performed at $50^{\circ} \mathrm{C}$ under a nitrogen atmosphere. A non-reacted chromium(VI) concentration was determined from the first end-point and a total iron concentration was obtained from the second endpoint. The iron(II) concentration was calculated by subtracting the non-reacted chromium(VI) concentra- tion from the initial one.

\section{Results and Discussion}

Redox reactions of chromium(VI) and iron(III) with cobalt(II) in the presence of 1,10-phenanthroline

The conditional redox potential of the $\mathrm{Fe}(\mathrm{III}) / \mathrm{Fe}$ (II) system in the presence of phen, $E_{\mathrm{Fe}}^{\prime}$, can be written as

$$
E_{\mathrm{Fe}}^{\prime}=E_{\mathrm{Fe}}^{\circ}+0.059 \log \frac{\alpha_{\mathrm{Fe}(\mathrm{II})(\mathrm{phen})}}{\alpha_{\mathrm{Fe}(\mathrm{III})(\mathrm{phen})}},
$$

where $\alpha$ refers to the side-reaction coefficient taking into account the complex formation of the relevant metals with phen: $\alpha_{\mathrm{Fe}(\mathrm{II})(\mathrm{phen})}=1+\sum \beta_{n(\mathrm{Fe}(\mathrm{II})(\mathrm{phen}))}[\mathrm{phen}]^{n}$ with $\beta_{n(\mathrm{Fe}(\mathrm{II})(\mathrm{phen}))}=\left[\mathrm{Fe}(\mathrm{II})(\text { phen })_{n}\right][\mathrm{Fe}(\mathrm{II})]^{-1}[\text { phen }]^{-n}(n=1,2,3)$ and $\alpha_{\mathrm{Fe}(\mathrm{III})(\mathrm{phen})}$ are defined similarly. It is obvious from Eq.(1) that $E_{\mathrm{Fe}}^{\prime}$ is higher than the standard redox potential of the $\mathrm{Fe}(\mathrm{III}) / \mathrm{Fe}(\mathrm{II})$ system, $E_{\mathrm{Fe}}^{\circ}$, in the presence of phen; that is, the oxidizing power of iron(III) increases because the formation constant, $\log \beta_{3}$, of the $\mathrm{Fe}(\mathrm{II})$ phen complex $\left(\log \beta_{3}, 21.3\right)$ is higher than that of the $\mathrm{Fe}(\mathrm{III})$-phen $\left(\log \beta_{3}, 14.1\right){ }^{15}$ Similarly, the conditional redox potential of the $\mathrm{Co}(\mathrm{III}) / \mathrm{Co}$ (II) system is lower than that of this system in the presence of phen. Vydra et al $^{7,8}$ reported the standard redox potential of the system $\mathrm{Co}$ (phen $)_{3}{ }^{3+} / \mathrm{Co}($ phen $) 3^{2+}$ to be $0.37 \mathrm{~V}$ by an analysis of the potentiometric titration curve of cobalt(II) with iron(III) in the presence of phen at pH 2. Thus, the reduction reaction of iron(III) with cobalt(II) should be favored in the presence of phen. On the other hand, the effect of phen on the redox reaction of cobalt(II) with chromium(VI) has already been studied potentiometrically. ${ }^{11}$ According to the results of the previous findings, the conditional redox potential of the $\mathrm{Co}(\mathrm{III}) / \mathrm{Co}$ (II) system was sufficiently lower than that of the $\mathrm{Cr}(\mathrm{VI}) / \mathrm{Cr}(\mathrm{III})$ system in the presence of phen at $\mathrm{pH} 1$ - 2. A potential change in the $\mathrm{Cr}(\mathrm{VI}) / \mathrm{Cr}$ (III) system was not observed under the same conditions. Thus, in the presence of phen, chromium(VI) and iron(III) should be easily reduced by cobalt(II). A titrimetric method for the successive determination of chromium(VI) and iron(III) with cobalt(II) was developed by using these two redox reactions. ${ }^{12}$ The method can be adapted to the successive titration of iron(II) and iron(III) by oxidizing iron(II) to iron(III) by a known amount of chromium(VI) before titration with cobalt(II). The first end-point corresponded to the reduction of chromium(VI), which was in excess over iron(II), to chromium(III) and the second one corresponded to the reduction of iron(III) (total iron) to iron(II) by cobalt(II) in the presence of phen. Therefore, a non-reacted chromium(VI) concentration was determined from the first end-point, and the iron(II) concentration was calculated by subtracting the non-reacted chromium(VI) concentration from the initial one. The initial iron(III) concentration was calculated by subtracting the iron(II) concentration from the total iron concentration. 


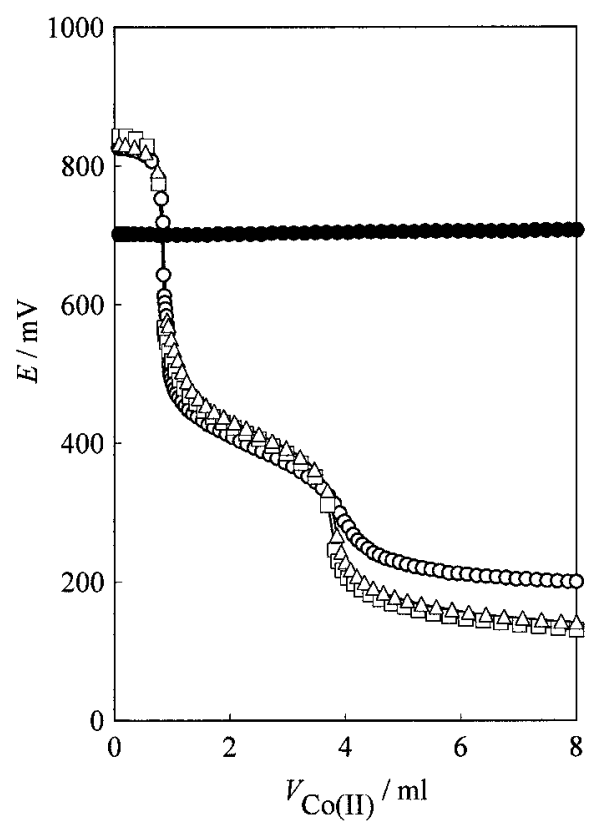

Fig. 1 Effect of the phen concentration on the successive titration curves of iron(II) and iron(III). Concentration of phen $\left(\mathrm{mol} \mathrm{dm}{ }^{-3}\right)$ : $(\bullet), 0 ;(\bigcirc), 2 \times 10^{-2} ;(\triangle), 5 \times 10^{-2} ;(\square)$, $8 \times 10^{-2}$. Other conditions as in the text.

Effect of variables on the successive titration of iron(II) and iron(III)

The optimum conditions for the titration of $5 \times 10^{-4}$ mol dm${ }^{-3}$ iron(II) and $1 \times 10^{-3} \mathrm{~mol} \mathrm{dm}^{-3}$ iron(III) with $1 \times 10^{-2} \mathrm{~mol} \mathrm{dm}^{-3}$ cobalt(II) were examined. All measurements were carried out at $50^{\circ} \mathrm{C}$.

The effect of the phen concentration on the titration curves was examined over the range $0-8 \times 10^{-2} \mathrm{~mol}$ $\mathrm{dm}^{-3}$ at $\mathrm{pH}$ around 1. The results are shown in Fig. 1 . Though a potential break was not obtained in the absence of phen, two remarkable potential breaks at the equivalence points were observed at higher phen concentrations than $2 \times 10^{-2} \mathrm{~mol} \mathrm{dm}^{-3}$, because the conditional redox potential of the $\mathrm{Co}$ (III)/Co(II) system decreased with increasing the phen concentration. Therefore, successive titrations of iron(II) and iron(III) could be performed in the presence of a phen concentration beyond $2 \times 10^{-2} \mathrm{~mol} \mathrm{dm}^{-3}$.

The effect of the $\mathrm{pH}$ on the titration curves was examined over the range $0.6-2.0$ in the presence of $2 \times 10^{-2}$ mol dm${ }^{-3}$ phen. A suspension of the precipitates was observed in the solution at $\mathrm{pH}$ 2.0. As shown in Fig. 2, the second end-point was not clearly detected at $\mathrm{pH} 0.6$ because of a decrease in the conditional redox potential of $\mathrm{Fe}(\mathrm{III}) / \mathrm{Fe}$ (II) system; that is, complexation of iron(II) with phen should not be favored at this $\mathrm{pH}$. Therefore, the successive titration of iron(II) and iron(III) with cobalt(II) in the presence of phen should be carried out at a $\mathrm{pH}$ around 1 .

The effect of the chromium(VI) concentration as an oxidizing agent was examined over the range $5 \times 10^{-4}$ $1.5 \times 10^{-3} \mathrm{~mol} \mathrm{dm}^{-3}$ in the presence of $2 \times 10^{-2} \mathrm{~mol} \mathrm{dm}^{-3}$ phen at $\mathrm{pH}$ around 1. Both potential breaks at the

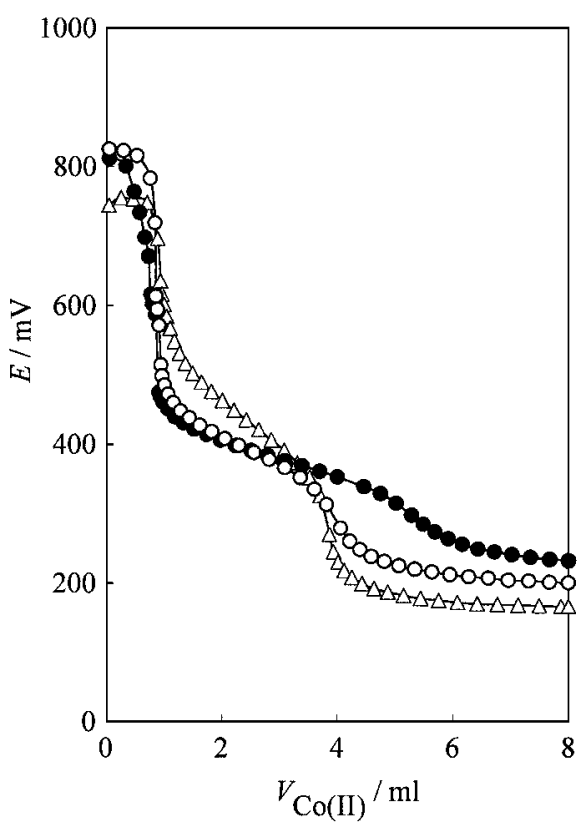

Fig. 2 Effect of the $\mathrm{pH}$ on the successive titration curves of iron(II) and iron(III). pH: $(\bullet), 0.6 ;(\bigcirc), 0.9 ;(\triangle), 1.5$. Other conditions as in the text.

equivalence points were observed at each chromium(VI) concentration. However, the recoveries became poorer with increasing the chromium(VI) concentrations. Therefore, a $5 \times 10^{-4} \mathrm{~mol} \mathrm{dm}^{-3}$ chromium(VI) concentration was chosen for the procedure.

\section{Determination of iron(II) and iron(III) in synthetic mixtures}

The successive potentiometric titration of iron(II) and iron(III) in synthetic mixtures was carried out over the ranges of $3 \times 10^{-4}-1 \times 10^{-3} \mathrm{~mol} \mathrm{dm}^{-3}$ iron(II) and iron(III) in the presence of $2 \times 10^{-2} \mathrm{~mol} \mathrm{dm}^{-3}$ phen at $\mathrm{pH}$ about 1 . The analytical results of iron(II) and iron(III) are given in Table 1. As can be seen in Table 1, the recoveries of both ions were satisfactory. The relative standard deviations of this method were 0.66 and $0.81 \%$ for four determinations of $5 \times 10^{-4} \mathrm{~mol} \mathrm{dm}^{-3}$ iron(II) and $1 \times 10^{-3} \mathrm{~mol} \mathrm{dm}^{-3}$ iron(III), respectively.

\section{Interferences}

The effect of foreign ions on the titration of a mixture of $5 \times 10^{-4} \mathrm{~mol} \mathrm{dm}^{-3}$ iron(II) and $1 \times 10^{-3} \mathrm{~mol} \mathrm{dm}^{-3}$ iron(III) was examined in the presence of $2 \times 10^{-2} \mathrm{~mol}$ $\mathrm{dm}^{-3}$ phen. The results are summarized in Table 2; a $\pm 3 \%$ error was considered to be tolerable. The following compounds and ions had no influence: $\mathrm{NaCl}, \mathrm{KNO}_{3}$ and $\mathrm{Mg}(\mathrm{II})\left(5 \times 10^{-3} \mathrm{~mol} \mathrm{dm}^{-3}\right) ; \mathrm{Ca}(\mathrm{II}), \mathrm{Al}(\mathrm{III}), \mathrm{Mn}(\mathrm{II})$, $\mathrm{Ni}(\mathrm{II}), \mathrm{Cu}(\mathrm{II}), \mathrm{Zn}(\mathrm{II})$ and $\mathrm{Pb}(\mathrm{II})\left(5 \times 10^{-4} \mathrm{~mol} \mathrm{dm}^{-3}\right)$. Vanadium $(\mathrm{V})$ caused a serious positive interference in the titration, because of the reduction of vanadium $(\mathrm{V})$ to vanadium(IV) by cobalt(II) under the experimental conditions. ${ }^{11}$ The tolerance limit of vanadium(V) was $1 \times 10^{-5} \mathrm{~mol} \mathrm{dm}^{-3}$ vanadium(V). Separations of iron(II) and iron(III) from this interfering ion by solvent extrac- 
Table 1 Successive potentiometric titration of iron(II) and iron(III) in synthetic mixtures

\begin{tabular}{cccccc}
\hline \multicolumn{3}{c}{ Taken $/ 10^{-3} \mathrm{~mol} \mathrm{dm}^{-3}$} & \multicolumn{2}{c}{ Found $/ 10^{-3} \mathrm{~mol} \mathrm{dm}^{-3}$} & \multicolumn{2}{c}{ Recovery, \% } \\
Fe(II) & Fe(III) & Fe(II) & Fe(III) & Fe(II) & Fe(III) \\
\hline 0.30 & 0.50 & 0.31 & 0.50 & 103 & 100 \\
0.30 & 1.00 & 0.31 & 0.99 & 103 & 99 \\
1.00 & 0.30 & 1.01 & 0.29 & 101 & 97 \\
0.50 & 0.50 & 0.49 & 0.50 & 98 & 100 \\
0.50 & 0.75 & 0.49 & 0.75 & 98 & 100 \\
0.50 & 1.00 & 0.50 & 1.00 & 100 & 100 \\
\hline
\end{tabular}

Table 2 Effect of diverse ions and compounds on the potentiometric titration of $5 \times 10^{-4} \mathrm{~mol} \mathrm{dm}^{-3}$ iron(II) and $1 \times 10^{-3} \mathrm{~mol} \mathrm{dm}^{-3}$ iron(III) with cobalt(II) in the presence of $2.0 \times 10^{-2} \mathrm{~mol} \mathrm{dm}^{-3}$ phen

\begin{tabular}{|c|c|c|c|c|c|}
\hline \multirow{2}{*}{ Ion or salt } & \multirow{2}{*}{ Added $/ \mathrm{mol} \mathrm{dm}^{-3}$} & \multicolumn{2}{|c|}{ Found $/ 10^{-3} \mathrm{~mol} \mathrm{dm}^{-3}$} & \multicolumn{2}{|c|}{ Recovery, \% } \\
\hline & & $\mathrm{Fe}(\mathrm{II})$ & $\mathrm{Fe}(\mathrm{III})$ & $\mathrm{Fe}(\mathrm{II})$ & $\mathrm{Fe}(\mathrm{III})$ \\
\hline $\mathrm{NaCl}$ & $5.0 \times 10^{-3}$ & 0.51 & 1.01 & 102 & 101 \\
\hline $\mathrm{KNO}_{3}$ & $5.0 \times 10^{-3}$ & 0.50 & 1.02 & 100 & 102 \\
\hline $\operatorname{Mg}(\mathrm{II})$ & $5.0 \times 10^{-3}$ & 0.50 & 0.99 & 100 & 100 \\
\hline $\mathrm{Ca}(\mathrm{II})$ & $5.0 \times 10^{-4}$ & 0.49 & 1.00 & 98 & 100 \\
\hline $\mathrm{Al}(\mathrm{III})$ & $5.0 \times 10^{-4}$ & 0.50 & 0.99 & 99 & 99 \\
\hline \multirow[t]{2}{*}{$\mathrm{V}(\mathrm{V})$} & $5.0 \times 10^{-5}$ & 0.48 & 1.11 & 96 & 111 \\
\hline & $1.0 \times 10^{-5}$ & 0.49 & 1.03 & 97 & 103 \\
\hline Mn(II) & $5.0 \times 10^{-4}$ & 0.49 & 0.98 & 98 & 98 \\
\hline $\mathrm{Ni}(\mathrm{II})$ & $5.0 \times 10^{-4}$ & 0.49 & 1.02 & 98 & 102 \\
\hline $\mathrm{Cu}(\mathrm{II})$ & $5.0 \times 10^{-4}$ & 0.50 & 1.01 & 99 & 101 \\
\hline $\mathrm{Zn}(\mathrm{II})$ & $5.0 \times 10^{-4}$ & 0.50 & 0.97 & 99 & 97 \\
\hline $\mathrm{Pb}(\mathrm{II})$ & $5.0 \times 10^{-4}$ & 0.49 & 1.01 & 98 & 101 \\
\hline
\end{tabular}

$\mathrm{A} \pm 3 \%$ error was considered to be tolerable.

tion and/or an ion-exchange procedure are necessary to avoid interference when large amounts of this ion coexist in the sample.

\section{Application to iron ore samples}

The proposed method was applied to the determination of the total iron in standard iron-ore samples (JSS No. 801-4, 814-1 and 850-4) and to the successive determination of iron(II) and iron(III) in a Mosan ironore sample (JSS No. 812-3) issued by the Japan Iron and Steel Federation. Decomposition of the former and the latter samples was carried out according to the JIS M 8212 (1994) and JIS M 8213 (1995) procedures, respectively. The results obtained by the proposed method are given in Tables 3 and 4. The digested sample solutions were diluted 25 times with $0.01 \mathrm{~mol} \mathrm{dm}^{-3}$ sulfuric acid before measurements. The analytical results were in good agreement with the certified values.

We gratefully acknowledge the financial support of this study by Grants-in-Aid for Scientific Research (No. 09640715) from the Ministry of Education, Science, Sports and Culture.
Table 3 Determination of total iron in standard iron-ore samples $^{\mathrm{a}}$

\begin{tabular}{lcc}
\hline \multirow{2}{*}{ Sample } & \multicolumn{2}{c}{ Fe in sample, \% $(\mathrm{m} / \mathrm{m})$} \\
\cline { 2 - 3 } & Proposed method $^{\mathrm{b}}$ & Certified value \\
\hline $\begin{array}{l}\text { Indian hematite } \\
\text { (JSS No. 801-4) }\end{array}$ & $65.56 \pm 0.86$ & $66.18 \pm 0.044$ \\
$\begin{array}{l}\text { Peru magnetite } \\
\text { (JSS No. 814-1) }\end{array}$ & $66.62 \pm 1.14$ & $65.70 \pm 0.087$ \\
$\begin{array}{l}\text { Marcona pellet } \\
\text { (JSS No. 850-4) }\end{array}$ & $65.80 \pm 1.43$ & $65.67 \pm 0.073$ \\
\hline
\end{tabular}

a. Issued by the Japan Iron and Steel Federation.

b. Average value for four determinations.

Table 4 Determination of iron(II) and iron(III) in a Mosan iron-ore sample ${ }^{\mathrm{a}}$

\begin{tabular}{lcc}
\hline & $\begin{array}{c}\text { Proposed method, } \\
\%(\mathrm{~m} / \mathrm{m})^{\mathrm{b}}\end{array}$ & $\begin{array}{c}\text { Certified values, } \\
\%(\mathrm{~m} / \mathrm{m})\end{array}$ \\
\hline $\mathrm{Fe}(\mathrm{II})$ & $21.08 \pm 0.54$ & $18.83 \pm 0.11$ \\
$\mathrm{Fe}(\mathrm{III})$ & $39.62 \pm 0.57$ & $41.12 \pm 0.074$ \\
\hline
\end{tabular}

a. Issued by the Japan Iron and Steel Federation (JSS No. 812-3).

b. Average value for four determinations.

\section{References}

1. T. M. Florence, Talanta, 29, 345 (1982).

2. E. Nakayama, Y. Suzuki, K. Fujiwara and Y. Kitano, Anal. Sci., 5, 129 (1989).

3. M. D. Luque de Castro and M. V. Cases, Analyst[London], 109, 413 (1984).

4. M. A. Anderson and F. M. M. Morel, Limnol. Oceanogr., 27, 789 (1982).

5. H. Hong and D. R. Kester, Limnol. Oceanogr., 31, 512 (1986).

6. E. P. Serjeant, "Potentiometry and Potentiometric Titrations", John \& Wiley and Sons, New York, 1984.

7. F. Vydra and R. Pribil, Talanta, 3, 103 (1959).

8. F. Vydra and R. Pribil, Talanta, 5, 44 (1960).

9. H. Itabashi, K. Umetsu, K. Satoh and T. Kawashima, Anal. Sci., 6, 721 (1990).

10. K. Umetsu, H. Itabashi, K. Satoh and T. Kawashima, Anal. Sci., 7, 115 (1991).

11. N. Teshima and T. Kawashima, Bull. Chem. Soc. Jpn., 69, 1975 (1996).

12. H. Katsumata, N. Teshima and T. Kawashima, Bull. Chem. Soc. Jpn., 70, 2151 (1997).

13. H. Katsumata, N. Teshima and T. Kawashima, Anal. Sci., 13, 825 (1997).

14. N. Teshima, H. Itabashi and T. Kawashima, Anal. Sci., 10, 207 (1994).

15. W. A. E. McBryde, "A Critical Review of Equilibrium Data for Proton- and Metal Complexes of 1,10-Phenanthroline, 2,2'-Bipyridyl and Related Compounds", Pergamon Press, Oxford, 1978.

(Received March 12, 1999) (Accepted April 30, 1999) 